\title{
Special Sense Organ System
}

National Cancer Institute

\section{Source}

National Cancer Institute. Special Sense Organ System. NCI Thesaurus. Code C13058.

Any one of the specialized organ systems, including the auditory, gustatory, olfactory, vestibular, and visual systems, which transmit signals from their respective organs to the brain via specialized somatic and visceral afferent fibers. 